\section{Trustworthy doctors in confidence building systems} M R Dibben, H T O Davies

Public trust in healthcare systems requires a balance to be struck between the macro concerns of "public" confidence and the microdynamics of "private" interpersonal trust between patients and health professionals

$\mathrm{T}$ he role of trust in public services has received increasing attention over the past decade. ${ }^{1}$ In the UK, for the most part, attention has only been focused on public trust in the wake of serious service failings-failings that have had such impacts on the national psyche that they are often recalled by a single name of place, perpetrator or victim (see box) - for example, in the police service (Stephen Lawrence, Soham), rail transport (the Paddington, Hatfield, and Potters Bar disasters), and farming/food policy (foot and mouth disease and BSE). British public health care (the NHS) has, in particular, come under intense scrutiny following widespread public dismay over numerous scandals (Alder Hey, Bristol, various malpractice cases at the General Medical Council and, most notorious of all, Harold Shipman). In each of these cases "public trust betrayed" has emerged as a common theme.

But what is "public trust"? Too often the term appears to be a convenient "catch all" expression used for making rather general statements about the relationships between groups (patients, service users, the public) and their service providers (doctors, hospitals, the NHS). Yet "trust" - the set of expectations that one party holds about another's likely behaviour in a situation entailing risk to that first party-is more usually something that resides within individuals than in groups. How, then, can we move from this individualised understanding of trust to notions of collective public trust in institutions and organisations?

Two papers in this issue of $Q S H C^{23}$ go some way towards bridging this important gap. In the first paper Calnan and Stanford ${ }^{2}$ use survey data to show that reporting by individuals of the extent of their trust in health services depends on the specific aspects of service enquired about. On average, respondents had a much lower level of belief that systems can deliver (that is, high quality, accessible, and timely care at reasonable cost) than confidence in the more immediate aspects of the doctor-patient encounter (for example, getting sufficient and considered attention from well trained doctors). In further analyses Calnan and Stanford suggest that overall assessments of public trust are driven more by patient perceptions of these micro aspects of patient care than the systems aspects of service delivery.

The second paper by Checkland $e t a l^{3}$ sheds considerable light on these empirical relationships by differentiating between trust and confidence. Public confidence is seen as being related to perceptions about the ability of extant systems to manage and deal with potential risks-for example, through regulation, measurement and governance. In contrast, public trust relates more to individuals' experiences of care delivery, being concerned with the interpersonal aspects of care and moral choices in the face of uncertainty. ${ }^{4}$ This very useful distinction enables some important linkages to be

\section{Tragedies and scandals in the UK with implications for "public trust"}

\section{Stephen Lawrence}

In April 1993, black teenager Stephen Lawrence was murdered by racist thugs at a bus stop in Eltham, south-east London. A bungled police investigation meant that no one has been convicted for his murder. A subsequent enquiry (the Macpherson report) blamed "institutional racism" for some of these failings.

\section{Soham}

In August 2002, two young girls were murdered in the village of Soham by a local school caretaker. The caretaker had been employed despite a history of allegations of sexual assault and rape, often involving under age girls. Police checks designed to prevent the employment of such people in sensitive positions failed to uncover this history.

\section{Paddington, Hatfield and Potters Bar}

These three significant rail accidents, causing death and injury, seriously undermined public confidence in the safety of rail systems and the associated regulatory frameworks.

\section{Foot and mouth disease}

The rapid spread of this highly infectious disease in the spring of 2001, and the ensuing attempts to control it, raised many questions about the intensive nature of food production and related animal welfare in the UK.

BSE

Bovine spongiform encephalopathy (BSE), more popularly known as "mad cow disease", is a disease of cattle first identified in 1986. Despite many government assurances to the contrary, it is now accepted that this animal disease has potential implications for human health.

\section{Alder Hay}

This scandal takes its name from a children's hospital in Liverpool where hundreds of organs were "harvested" from dead children and stored for medical experimentation without the approval of the grieving parents. Subsequent investigations showed the practice to have taken place elsewhere across the UK and have led to legislation tightening up on the retention of human tissue for research.

Bristol

Higher than expected mortality rates of paediatric cardiothoracic surgery patients in the Bristol Royal Infirmary led to professional misconduct proceedings against three doctors and a subsequent public inquiry.

\section{Harold Shipman}

A single handed GP from Hyde, Greater Manchester, Harold Shipman was found guilty in the criminal courts of the murders of 15 of his patients. Subsequent enquiries suggest that the number actually murdered could have exceeded 200. 
made between micro and macro perceptions of public services.

Repeated interactions between individual patients and the healthcare professionals who care for them provide those individuals with a series of specific experiences on which to draw. ${ }^{5}$ As a result, whatever public confidence they bring with them to the clinic is soon superseded by a far more direct and concrete set of experiences that inform their level of trust. $^{6}$ Calnan and Stanford's work suggests that it is these experiences-rather than abstract knowledge of systems-that most closely informs subsequent overall assessments of what they term "trust". However, public alarm over periodic scandals and crises may be articulated as a loss of trust and lead to calls for more systems of scrutiny and control to be put in place. $^{7}$ These systems in turn may modulate the nature of subsequent care giving episodes, impacting on trust. Thus, two distinct but interacting processes may be being conflated and muddled because of the non-specific use of terms such as "public trust". As a result, concerns and remedies may be badly mismatched.

These papers therefore pose two very important challenges for policy makers and service managers. Firstly, they emphasise the primacy of interpersonal contacts in maintaining and moulding public perceptions. Notwithstanding the need for confidence building systems, greater attention may need to be paid to the microdynamics of the professional/ user interface. Secondly, these papers highlight the potential interactions between these macro and micro issues and further suggest that such interactions may work in both directions. "Public" confidence building systems may hamper the development of interpersonal (that is, "private") trust building consultations between patients and professionals. We suggest that this is because explicit and systemic measurement of accountability can serve to lessen the value placed in the implicit and personal trust relationships (with, for example, patients, clients, relatives or even co-workers) that ultimately enable professional work. ${ }^{8}$ At the same time, however, excellent interpersonal skills and the development of high levels of "private trust" may serve to shield the incompetent (Dr Shipman, of course, was very well regarded by many of his patients).

Effective and safe healthcare systems that command public respect thus need serious attention to be paid to both the macro concerns of "public" confidence building systems and the microdynamics of "private" interpersonal trust between all the individuals concerned with health delivery (patients, nurses, clinicians, managers). In both these areas there is potential for dysfunctional consequences as well as desirable outcomes. Getting the balance right will be difficult, but neither approach on its own will suffice.

Qual Saf Health Care 2004;13:88-89.

doi: 10.1136/qshc.2004.010173

\section{Authors' affiliations}

M R Dibben, Commerce Division, Lincoln University, Canterbury, New Zealand H T O Davies, Centre for Public Policy \& Management, School of Management, University of St Andrews and Associate Director, Social Dimensions of Health Institute at the Universities of Dundee and St Andrews, St Andrews, Fife, UK

Correspondence to: Professor H T O Davies, Centre for Public Policy \& Management, School of Management, University of St Andrews, St Andrews, Fife KY16 9AL, UK;

hd@st-and.ac.uk

\section{REFERENCES}

1 Davies HTO. Falling public trust in health services: implications for accountability. J Health Serv Res Policy 1999:4:193-4.

2 Calnan MW, Stanford E. Public trust in health care: the system or the doctor? Qual Saf Health Care 2004; 13:92-7

3 Checkland K, Marshall M, Harrison S. Rethinking accountability: trust versus confidence in medical practice. Qual Saf Health Care 2004;13:130-5.

4 Smith C. Trust and confidence: possibilities for social work in "high modernity". Br J Social Work 2001:31:287-305.

5 Dibben MR, Eley-Morris S, Lean MEJ. Situational trust and co-operative partnerships between physicians and their patients: a theoretical explanation transferable from business practice. $Q J \mathrm{Med}$ 2000;93:55-61

6 Dibben MR, Lean MEJ. Achieving compliance in chronic illness management: illustrations of trust relationships between physicians and nutrition clinic patients. Health, Risk and Society 2003;5:241-58

7 Davies HTO, Shields A. Public trust, and accountability for clinical performance: lessons from the media reporting of the Bristol enquiry. J Eval Clin Pract 1999;5:335-42.

8 Davies HTO, Lampel J. Trust in performance indicators? Qual Health Care 1998;7:159-62.

\section{Are we suffering from change fatigue? P Garside}

\section{Clinicians must be motivated to accept the changes necessary to achieve improvements in quality and performance}

Q uality improvements require change. Performance improvements require change. When a health system aspires to both over a sustained period there is a serious risk of "change fatigue" - key players getting tired of new initiatives and the way they are implemented-invariably the key players needed to make the changes work and bring in the improvements.

The National Health Service (NHS) in England has pursued improvements in performance and quality for almost 10 years, but particularly since the Labour government came to power in $1997 .{ }^{12}$ Significant extra funding has been made available by central government, and structures and systems have been established to ensure that the NHS "modernises" its practices. These programmes have achieved results: waiting times are down for elective procedures, access to care has improved, and more resources for staff and treatment are available to managers and clinicians. The improvements in performance have been achieved through the relentless application of targets via a managerial regime working "top down" in the NHS. Quality and service improvements are encouraged through a wide range of initiatives embraced principally through the Modernisation Agency, an agency of government focused on changing processes and systems to improve both quality and performance.

In this month's QSHC Gollop et al address the issue of scepticism and resistance to changes in working practices. The authors rightly point out that this resistance is principally among medical staff, and that the reasons include personal reluctance to change, misunderstanding of the aims of improvement programmes, and a dislike of the methods by which the programmes have been promoted.

Managers cope with change in a different way from clinicians (accepting that many clinicians have significant managerial responsibility). It has become almost customary practice for 
managers to pursue new centrally dictated imperatives and targets in publicly funded health systems. Clinicians are motivated by different incentives and dwell in a professional domain where individual professional autonomy is paramount and allegiances tend to be to professional societies and peers. ${ }^{4}$ They dwell in these domains for a lengthy period of time, in contrast to managers whom they perceive to move through the system as quickly as any number of new initiatives ("revolving entities"). Gollop et al acknowledge that doctors are the key players to engage with the change process, and the ones offering the most powerful resistance. Ask if clinicians are suffering from change fatigue and the answer is most probably "yes". Delve a little deeper and we may understand why.

Clinicians want to change things for the better for their patients and for working practices. They perceive an endless stream of initiatives, see many of them "fail" and reappear with a new name, see conflicting directions of change, and a plethora of initiatives so great that they fail to see the final purpose or connecting logic. They believe that "managerialism" has eroded their autonomy. What is probably more important is that they do not have the space or the time in which to pursue these programmes. Publicly funded health systems do not offer the luxury of resources which similar change programmes receive in private industry. There is little time in their personal schedules, little dedicated resource, and little room to manoeuvre to make changes happen-sometimes, literally, no physical space to rearrange services.

The answers should be in the field of organisational development. Ironically, this is not a body of knowledge and practice generally accepted by clinicians. ${ }^{5}$ What does motivate people is a shared vision "hooking" into personal desires to improve practice, evidence that the process behind the programme might work, and resources to help them do it. Trust in the leader and in the process taking change forward is also essential. Leadership is critical as people cannot simply be ordered to change. There must be a sense that the prize at the end of the change process is greater than the sacrifices they are making.

One major change programme which did engage clinicians successfully is clinical governance. ${ }^{1}$ This major programme in the NHS focuses on the organisation's duty of quality and provides clinical and management responsibility for systems to ensure quality of service. As a new development it probably encountered the least resistance of any of the new national initiatives within the NHS-why? It was "going with the clinical grain" in terms of service improvement and had a set of aims which were clearly understood. Furthermore, its title and the terminology seemed to make sense and resources were attached for its implementation over a programmed time scale. Contrast this with the introduction of so-called hospital "re-engineering" initiatives in the early and mid 1990s-frightening terminology, minimal evidence base from the US, and a patchy process of introduction. It was a good idea badly implemented and it failed to engage the majority of clinicians.

Are we suffering change fatigue? There is a danger that we are. Can we avoid change fatigue among the followers we wish to create? The answer is "yes", if we align the incentives such that there is congruence of aims, lead in the right way, avoid jargon, attach resources and time, and engender trust through delivery. Difficult-but worth it.

Qual Saf Health Care 2004;13:89-90.

doi: 10.1136/qshc.2003.009159

Correspondence to: Ms P Garside, Judge Institute of Management, University of Cambridge, Cambridge CB2 1AG, UK; pg@pamgarside.com

\section{REFERENCES}

1 Department of Health. Quality in the new NHS: a first class service. London: The Stationery Office, 1998.

2 Department of Health. The NHS plan. London: The Stationery Office, 1998.

3 Gollop R, Whitby E, Buchanan D, et al. Influencing sceptical staff to become supporters of service improvement: a qualitative study of doctors' and managers' views. Qual Saf Health Care 2004;13:108-14.

4 Sutherland K, Dawson S. Power and quality improvement in the new NHS: the roles of doctors and managers. Qual Health Care 1998;7(Suppl):S16-S23.

5 Garside P. Organisational context for quality: lessons from the fields of organisational development and change management. Qual Health Care 1998;7(Suppl):S8-S15.

\section{Learning from primary care malpractice: past, present and future}

\section{B Hurwitz}

\section{Understanding of UK primary care malpractice lags behind knowledge of US primary care malpractice}

\begin{abstract}
"Medications that clean bile and phlegm are a source of danger, and of blame for the person treating". Hippocrates. Affections 33.
\end{abstract}

$\mathrm{T}$ he tangled relations between disease, treatment, patient harm, medical fallibility, and physician culpability have been debated since classical times. But it is only historically recently that actions alleging negligence by doctors have become a commonplace feature of the health care landscape.

One hundred years ago an experienced Scottish judge, while hearing a legal case against an Edinburgh general practitioner (see box), commented on its rarity: "This action is certainly one of a particularly unusual character. It is an action of damages against a medical man. In my somewhat long experience I cannot remember having seen a similar case before." ${ }^{2}$

Only a century later the medicolegal landscape of health care could hardly be more different. In the year 2000 the UK General Medical Council received 5000 complaints which alleged doctors' misconduct or poor performance and National Health Service (NHS) hospitals in England faced 23000 outstanding claims for compensation. ${ }^{3}{ }^{4}$ The annual incidence of NHS written complaints concerning GPs' behaviour or the organisation of primary health care in 2001 relating to GPs and community dentists amounted to 44000 , an increase of $12 \%$ on the previous year and an overall increase of $20 \%$ since the current complaints procedure was implemented in 1996. Although legal cases against GPs 
On 14 April 1900 a GP, Dr Murray, diagnosed erysipelas in the finger of a grocer's right hand brought on from a scratch sustained on a rusty nail. Dr Murray wrote out a prescription for a medicine and a linseed and oatmeal poultice. Two days later the GP visited Mr Farquhar at home and continued with the poultice treatment saying he would call again the following day. But Dr Murray did not call back as promised, and the patient's wife wrote to the GP on 25 April asking him to come immediately to examine the finger. The following day Mr Farquhar was visited by a $\mathrm{Dr}$ Mackenzie who informed him that Dr Murray was now on holiday and that he was looking after the practice. Dr Mackenzie told him that no message or instructions about his medical condition had been left by Dr Murray and that, prior to his wife's letter, Dr Mackenzie had known nothing about him. After examining the finger he declared it had been poulticed too long and he changed the prescription. However, the finger eventually required amputation.

Mr Farquhar sued Dr Murray on the grounds that he had shown "a gross neglect of his professional duty" by breaking his undertaking to call again and by failing to monitor his finger. In absenting himself from his practice without arranging for medical attendance, Dr Murray's patient also alleged "a culpable want of attention and care" by the GP.

remain relatively uncommon in the UK (a high proportion of claims settle before trial), the Medical Protection Society observed a tenfold increase in the number of claims dealt with on behalf of its GP membership between 1989 and 1998, and estimated that 3.6\% of its GP members would face legal action as a result of work undertaken in the previous 12 months. ${ }^{6}$

In depicting a pre-NHS patient's attempt-unsuccessful in the event-to gain redress for harm he believed had been caused by a GP's failure to arrange reasonable monitoring and follow up, the case of Farquhar v Murray tellingly foreshadowed many aspects of modern day claims. As Phillips and colleagues convincingly show in a study in this issue of QSHC of 26126 malpractice claims lodged against US primary care physicians, those judged to result from negligence $(23 \%$ of the total) feature failures of diagnosis (34\%) and monitoring $(16 \%)$, with poor communicationproblems with records or inter-doctor communication-being a major contributing factor on $9 \%$ of occasions. ${ }^{7}$ Their study of Physician Insurers Association of America malpractice claims data significantly adds to the epidemiological understanding of conditions associated with claims for clinical negligence in primary care, and shows that certain medical conditions are much more likely than others to generate a claim-the diagnosis of appendicitis, for example, being some 25 times more likely on their data to generate a claim grounded in negligence than the diagnosis of breast cancer.

Other US researchers have analysed data sets relevant to malpractice. A study of primary care physicians in Colorado and Oregon compared doctors not facing malpractice claims with those with such claims; those without claims had significantly longer consultations (18.3 v 15 minutes), used more orientating statements (explaining what is likely to happen next), more facilitating statements (asking patient opinions and checking understanding), laughed more, and used more humour in consultations than did physicians with claims. Consultation length and physician affect (particularly laughter and behaviour demonstrative of concern, approval and empathy) were found to predict physician claims status. ${ }^{8}$ This association of facets of communication style with the likelihood of facing or having faced malpractice suits is strengthened by the findings of a more recent study which examined standardised extracts from 114 taped conversations of office visits between community practising surgeons and patients. The conversations were rated for warmth, hostility, dominance, and anxiety based on analysis of tone and content. Controlled for content, ratings of higher dominance identified surgeons with previous claims compared with those who had no claims, whereas greater concern/anxiety in their tone of voice identified those without claims (OR $2.74,95 \%$ CI 1.16 to 6.43 for dominance; OR $0.4695 \%$ CI 0.21 to 1.01 for concern/ anxiety). ${ }^{9}$

These studies build on previous analyses of US primary care malpractice data sets: a study in Florida covering a 13 year period of information found primary care doctors with a favourable claims profile to be older but no more likely to have more prestigious professional credentials, to have qualified in the USA or Canada, to be in solo or group practice, or to be involved in research or teaching than doctors with an unfavourable claims profile. ${ }^{10}$ Although such data sets cannot always allow for confounding-from unstudied differences in, for example, patient complexity (case mix) or physician interpersonal skills ${ }^{11}$ — such data, when properly analysed, can identify aspects of medical practice, organisation, and interpersonal behaviour likely to lead to malpractice claims. Because malpractice claims are in part the expression of patient expectation and societal and legal arrangements for redress and compensation, US findings cannot easily be generalised to other countries. UK organisations which hold comparable data sets should make them available, with appropriate safeguards, to independent researchers who can learn much from the research questions and approaches taken by their US counterparts.

Qual Saf Health Care 2004;13:90-91. doi: 10.1136/qshc. 2004.010470

Correspondence to: Dr B Hurwitz, Department of English, King's College, London WC2R 2LS, UK; brian.hurwitz@kcl.ac.uk

\section{REFERENCES}

1 Jouanna Jacques (translated by DeBevoise MB) Hippocrates. Baltimore and London: Johns Hopkins University Press, 1999:158

2 Farquar v Murray 3F, 859-64.

3 General Medical Council. GMC Council Minutes May 2000 Section 9. http://www.gmc-uk.org.

4 Report by the Comptroller and Auditor General. Handling clinical negligence claims in England. HC 403 Session 2000-2001. London: The Stationery Office, 2001.

5 Department of Health. http://www.doh.gov.uk/ Advanced Search Results (accessed February 2004).

6 Dyer C. GPs face escalating litigation. BMJ 1999;318:830.

7 Phillips RL, Bartholomew LA, Dovey S, et al. Learning from malpractice claims about negligent, adverse events in primary care in the United States. Qual Saf Health Care 2004; 13:121-6.

8 Levinson W, Roter DL, Malloly JP, et al. Physician-patient communication. The relationship with malpractice claims among primary care physicians and patients. JAMA 1997:277:553-9.

9 Ambady N, Laplante D, Nguyen T, et al. Surgeons' tone of voice: a clue to malpractice history. Surgery 2002;132:5-9.

10 Sloan FA, Mergenhagen PM, Burfield, et al. Medical malpractice experience of physicians. JAMA 1989;262:3291-7.

11 Ly J, Dawson J, Young P, et al. Malpractice claims against family physicians. Are the best doctors sued more? J Fam Pract 1999;48:23-9. 